\title{
Robotics in thoracic surgery: Applications and outcomes
}

\author{
Thomas A. D'Amico, MD
}

See related article on page 54

From the Department of Surgery, Duke University Medical Center.

Received for publication Dec 13, 2005; accepted for publication Dec 13, 2005.

Address for reprints: Thomas A. D'Amico, MD, Department of Surgery, Duke University Medical Center, Box 3496, Durham, NC 27710 (E-mail: damic001@mc.duke.edu).

J Thorac Cardiovasc Surg 2006;131:19-20

$0022-5223 / \$ 32.00$

Copyright () 2006 by The American Association for Thoracic Surgery

doi:10.1016/j.jtcvs.2005.09.007
$\mathrm{R}$ obotics has been used in numerous surgical procedures, but with few exceptions, this technologic advance has not been translated into improved outcomes. Many robotic applications have been unveiled as the manifestation a new idea in search of an application. The principal advantages of robotic assistance in surgical intervention are the greater degree of instrumental articulation and motion scaling. ${ }^{1}$ However, despite these recognized technical advantages, the demonstration of superior results has been disappointing.

A significant clinical application for surgical robotics has been for resection of prostate cancer. In a prospective nonrandomized trial comparing robotic with conventional radical retropubic prostatectomy among 60 patients, Menon and colleaguesr ${ }^{2}$ found that the robotic approach significantly reduced intraoperative blood loss and postoperative pain compared with the open approach. Furthermore, although the mean length of stay for patients in the conventional group was 4 days, two thirds of men undergoing robotic prostatectomy were discharged in less than 23 hours.

Robotic mitral valve surgery is also gaining acceptance, although there are no randomized studies that demonstrate superiority compared with the conventional approaches. In a recently published prospective series of 38 consecutive patients, Nifong and associates ${ }^{3}$ reported no operative deaths, strokes, or conversions to open sternotomy. The average total operative time was less than 5 hours, and the mean length of stay was 4 days. $^{3}$ In a recent phase II multicenter trial of robotic mitral valve surgery, total robot, aortic crossclamp, and cardiopulmonary bypass times were 78 minutes, 2.1 hours, and 2.8 hours, respectively. At 1 month of transthoracic echocardiography, only $8 \%$ had grade 2 mitral regurgitation. There were no deaths, strokes, or device-related complications. ${ }^{4}$

The use of robotics is also being studied in general thoracic surgery, including lobectomy, ${ }^{5}$ esophagectomy, ${ }^{6}$ and various other procedures, ${ }^{7}$ demonstrating safety and feasibility. The study by Park and coworkers ${ }^{8}$ in this issue of the Journal describes their experience in developing a standardized approach to robotic lobectomy. As with most thoracic procedures that can be performed robotically, the potential advantages of articulation in 7 degrees and motion stability are probably not fully realized in robotic lobectomy. The growing experience with thoracoscopic lobectomy suggests that the limitations imposed by the thoracoscopic technique, such as port placement and visualization, are easily overcome. ${ }^{9,10}$

However, there are several disadvantage of the robotic system. One important disadvantage is the loss of tactile sense in current systems. Although thoracoscopic lobectomy might alter tactile feedback compared with open thoracotomy, much information is nevertheless communicated to the surgeon's hands. The significance of this feedback is difficult to quantify, and it is possible that robotic systems will be designed to transmit tactile information in the future.

In addition, the instrumentation that is available for use robotically is limited in comparison with the instrumentation available for thoracoscopic or open lobectomy. It is unlikely that the same spectrum of instrumentation will be developed for the robot. Perhaps the superior articulation of the robotic system will compensate for the inferior selection of instrumentation.

Also, the time required to assemble the robotic instrumentation is significant, as is the increase in the overall operative time. In this study the median operative time was 218 minutes, and the median room time was 306 minutes. $^{8}$ Although the total operative times are likely to decrease with experience, as they have with thoraco- 
scopic lobectomy, ${ }^{9,10}$ the mandatory set-up time seems prohibitive for most surgeons.

Currently, the robotic technique appears to require 3 experienced surgeons ${ }^{8}$ compared with 1 for the thoracoscopic technique. ${ }^{9,10}$ In the short term this will negatively affect resident training at institutions that favor the robotic approach. In addition, the introduction of robotic and other technology into the operating room has necessitated the development of training programs to teach surgeons how to use the technology. It will be important for surgeons to demonstrate mastery of these techniques before including them in practice.

In summary, the analysis by Park and coworkers ${ }^{8}$ is an important and commendable effort to study and standardize the robotic technique. The outcomes of the robotic technique should be compared with thoracoscopic techniques, which are associated with significant advantages vis a vis thoracotomy, including shorter length of stay, less pain, preserved pulmonary function, and faster return to full activity. ${ }^{9} 10$ As experience with robotic lobectomy improves, the disadvantages might become less important, and the advantages might become more well defined. Although it is not likely that a randomized study would be funded to compare robotic lobectomy with alternatives, some appraisal must be made to assess overall effectiveness, including cost-effectiveness. Surgeons who study technologic advances, such as robotic lobectomy, will be better prepared to adapt, to lead the field, to develop more effective techniques, and to improve surgical outcomes. ${ }^{1}$

\section{References}

1. Prasad SM, Prasad SM, Maniar HS, Chu C, Schuessler RB, Damiano RJ Jr. Surgical robotics: impact of motion scaling on task performance. J Am Coll Surg. 2004;199:863-8.

2. Menon M, Tewari A, Baize B, Guillonneau B, Vallancien G. Prospective comparison of radical retropubic prostatectomy and robot-assisted anatomic prostatectomy: the Vattikuti Urology Institute experience. Urology. 2002;60:864-8.

3. Nifong LW, Chu VF, Bailey BM, Maziarz DM, Sorrell VL, Holbert D, et al. Robotic mitral valve repair: experience with the da Vinci system. Ann Thorac Surg. 2003;75:438-42.

4. Nifong LW, Chitwood WR, Pappas PS, Smith CR, Argenziano M, Starnes VA, et al. Robotic mitral valve surgery: a United States multicenter trial. J Thorac Cardiovasc Surg. 2005;129:1395-404.

5. Ashton RC, Connery CP, Swistel DG, DeRose JJ. Robot-assisted lobectomy. Ann Thorac Surg. 2004;78:259-65.

6. Espat NJ, Jacobsen G, Horgan S, Donahue P. Minimally invasive treatment of esophageal cancer: laparoscopic staging to robotic esophagectomy. Cancer J. 2005;11:10-7.

7. Bodner J, Wykypiel H, Wetscher G, Schmid T. First experiences with the da Vinci operating robot in thoracic surgery. Eur J Cardiothorac Surg. 2004;25:844-51.

8. Park BJ, Flores RM, Rusch VW. Robotic-assistance for video-assisted thoracic surgical lobectomy: technique and initial results. $J$ Thorac Cardiovasc Surg. 2006;131:54-9.

9. Daniels LJ, Balderson SS, Onaitis MW, D'Amico TA. Thoracoscopic lobectomy: a safe and effective strategy for patients with stage I lung cancer. Ann Thorac Surg. 2002;74:860-4.

10. Demmy TL, James TA, Swanson SJ, McKenna RJ Jr, D'Amico TA. Troubleshooting VATS lobectomy. Ann Thorac Surg. 2005;79:174453. 